Article

\title{
Physiological and Biochemical Responses of Two Cotton (Gossypium hirsutum L.) Cultivars Differing in Thermotolerance to High Night Temperatures during Anthesis
}

\author{
Dimitra A. Loka ${ }^{1, *}$ and Derrick M. Oosterhuis ${ }^{2}$ \\ 1 Institute of Industrial and Forage Crops, Hellenic Agricultural Organization, 41335 Larisa, Greece \\ 2 Department of Crop, Soil and Environmental Sciences, University of Arkansas, Fayetteville, AR 72704, USA; \\ oosterhu@uark.edu \\ * Correspondence: dimloka@gmail.com; Tel.: +30-2410-671300
}

Received: 30 July 2020; Accepted: 15 September 2020; Published: 16 September 2020

\begin{abstract}
Heat stress constitutes a major threat to crop production, and according to climatic projections, night temperatures are expected to increase faster and to a greater extent compared to day temperatures. While extensive research has been dedicated to the effects of higher than optimum day temperatures on cotton physiology, metabolism, and yield, and while heat-tolerant cotton cultivars have been introduced, the responses of such heat-tolerant cultivars to high night temperatures have not been evaluated. The objective of this study was to assess the efficiency of heat-tolerant cultivars to high night temperatures stress by monitoring the physiological and biochemical responses of two cotton cultivars, differing in thermotolerance, subjected to higher than optimum night temperatures, during anthesis. To that end, growth chamber experiments were conducted using two cotton cultivars differing in thermotolerance, namely ST5288B2RF (thermosensitive) and VH260 (thermotolerant). Treatments consisted of normal day/night temperatures $\left(32 / 24{ }^{\circ} \mathrm{C}\right)$ and high night temperatures $\left(32 / 30^{\circ} \mathrm{C}\right)$ for 2 weeks at flowering (approximately 8 eight weeks after planting). The results indicated that VH260 was more thermotolerant than ST5288 even under conditions of high night temperature stress, as it managed to maintain its net photosynthetic rates, cell membrane integrity, as well as pistil carbohydrate contents and ultimately achieved higher total reproductive weight. It was concluded that heat tolerance of thermotolerant cultivars selected under conditions of high day temperatures is also conserved under high night temperatures, while net photosynthetic rates and cell membrane integrity can be utilized as selection traits for heat tolerance under either high day or night temperatures.
\end{abstract}

Keywords: antioxidant; carbohydrate content; cotton; flowers; gas exchange; heat stress

\section{Introduction}

Heat stress significantly restricts crop growth and compromises plant production around the world despite the several mechanisms evolved by the plants in order to alleviate adverse environmental conditions [1,2]. According to climate reports, average global temperature has been rising over the last century and at the current rates of greenhouse gas emissions, a further increase is projected by the end of the 21st century [3]. Interestingly, due to expected increases in cloudiness and concomitant decreases in heat radiant loss, night temperatures are anticipated to rise faster and to a larger extent compared to daytime temperatures [4]. Higher than optimum temperatures during the day and their negative effects on plant physiology, biochemistry, and yield have been extensively investigated $[1,5,6]$. 
Substantial variability among species and genotypes has been recorded [5,7]; however, the response of heat tolerant varieties to high night temperatures has not been tested.

A negative correlation between high night temperatures and yield has been revealed by past research on several crops such as wheat (Triticum aestivum L.) [8], soybean (Glycine max L.) [9], sorghum (Sorghum bicolor L.) [10], cowpea (Vigna unguiculata L.) [11], and rice (Oryza sativa L.) [12]. Additionally, it has been reported that when high night temperatures coincide with the plant's reproductive stage, their effect on yield becomes detrimental due to increases in rates of floral abscission, male sterility, and floral bud suppression $[8,13,14]$.

Cotton (Gossypium hirsutum L.) may be considered a well-adapted crop to hot and semi-arid areas, since it originates from such areas; however, higher than optimum day temperatures have been shown to adversely affect its physiology and yield due to decreases in leaf photosynthetic rates and increases in respiration that result in limited carbohydrate availability to reproductive structures and consequently yield reductions through increased fruit abscission and reduced fruit set, as well as decreased boll size and seed number $[15,16]$. Similar to those observations, yield reductions due to lower boll setting [17], higher fruit shedding rates [18], and reduced number of seeds per locule and boll [19] have been reported for cotton when increased night temperatures occurred during its reproductive phase. Further research additionally revealed that high night temperatures increased cotton leaf respiration rates, with concomitant decreases in leaf photosynthetic rates, when the stress was applied during their early reproductive period [20].

In order to safeguard cotton production against the adverse effects of climate change, a concerted effort has been undertaken for breeding for heat tolerance, and several cotton cultivars, able to maintain their yield output under heat stress conditions, have been selected through the use of physiological, biochemical, and morphological parameters [15,21-24]. As such, heat tolerance in cotton has been associated with maintenance of leaf photosynthesis [22,23], especially of the subtending to a flower/boll leaf [25], and sufficient supply of assimilates to the reproductive structures, reduced leaf electrolyte leakage [26], as well as increased pre-stress antioxidant capacity and maintenance of ATP levels [23]. Nevertheless, those associations have been evaluated only under conditions of high day temperatures. Taking into consideration that night temperatures are expected to rise faster and to a larger extent than day temperatures, the efficiency of heat-tolerant varieties to heat stress occurring during the night is evidently important to be evaluated in order to provide breeders with a potentially new selection target. To that end, the objectives of this study were to monitor the effects of high night temperatures on the subtending leaf's photosynthesis and respiration, electrolyte leakage, and ATP levels, as well as on the levels of the antioxidant glutathione reductase, and soluble carbohydrate content of the flower and its subtending leaf of two cotton cultivars differing in heat-tolerance. It was hypothesized that the contrast in their thermotolerance cultivars would differ in their physiological and biochemical responses to high night temperatures and that would ultimately result in significant differences in their number of reproductive structures and total reproductive dry weight.

\section{Materials and Methods}

Growth chamber studies were conducted and repeated at the Altheimer Laboratory, University of Arkansas. Cotton (Gossypium hirsutum L.) cultivar ST5288B2F, a standard cultivar widely planted in the cotton belt, and VH260, a thermotolerant cultivar from Pakistan [22], were planted in 2 L pots containing horticulture mix \#2 (SunGro Distribution Inc., Bellevue, WA, USA). Pots were arranged in two growth chambers (Conviron PGW36, Conviron Inc., Winnipeg, Canada) that were equipped with incandescent and fluorescent lamps and set for a $14 \mathrm{~h}$ photoperiod with a photosynthetic flux density (PPFD) of $800-850 \mu \mathrm{mol} / \mathrm{m}^{2} \mathrm{~s}$ and a relative humidity of $60 \%$. Half-strength Hoagland's nutrient solution was applied daily to all pots in order to maintain adequate nutrients and water. Plants were grown until the flowering stage (approximately 8 weeks after planting) under normal day/night temperatures of $32 / 24{ }^{\circ} \mathrm{C}$ (maximum during the day, minimum during the night, respectively) simulating a normal diurnal variation. At flowering, the night temperatures on one of the two chambers were raised 
to $30{ }^{\circ} \mathrm{C}$ for $10 \mathrm{~h}$ at the start of the dark period $(2000 \mathrm{~h}-0600 \mathrm{~h})$ with a gradual decrease to $24{ }^{\circ} \mathrm{C}$, for an overall duration of two weeks, while the control plants remained under normal conditions $\left(32 / 24{ }^{\circ} \mathrm{C}\right)$. First position white flowers and their subtending leaves (LSWF) from main-stem nodes 8 and 10 were collected at the end of the first and second week, respectively, for determination of soluble carbohydrates, glutathione reductase, adenosine triphosphate (ATP), and electrolyte leakage. The study was repeated twice. In order to account for any possible differences between growth chambers, the growth chamber used for the high night temperature treatment $\left(32 / 30^{\circ} \mathrm{C}\right.$, day/night) in the first study was used for the control treatment $\left(32 / 24{ }^{\circ} \mathrm{C}\right.$, day/night) in the second study. No significant effect on any of the parameters monitored was found between the two studies $(p>0.05)$, and the data were combined from the two consecutive studies for statistical analysis.

\subsection{Leaf Gas Exchange Measurements}

A CI-340 handheld photosynthesis system (CID Bioscience, Inc., Camas, WA, USA) was used to determine net photosynthetic and respiratory rates for the attached subtending to the first position flower leaf from the 8th and 10th node of each plant. Measurements of photosynthesis and respiration were taken at $1200 \mathrm{~h}$ and $2300 \mathrm{~h}$, respectively, and the results were expressed as mmol m $\mathrm{m}^{-2} \mathrm{~s}^{-1}$. Measurements of respiration were taken $3 \mathrm{~h}$ into the dark period in order to avoid the respiratory burst that follows the end of the light period.

\subsection{Leaf Electrolyte Leakage Measurements}

Electrolyte leakage was measured according to Martineau et al. [27] with modifications. Five disks were punched from similar interveinal areas of the leaf subtending a flower and placed in closed vials filled with $10 \mathrm{~mL}$ of double deionized water and incubated at $25^{\circ} \mathrm{C}$ for $48 \mathrm{~h}$ in the dark. After this period, the electrical conductivity of the solution (L1) of all samples was determined using a single probe conductivity meter (Thermo Orion Model 115, Beverly, MA, USA). Subsequently, the vials were placed in a boiling water bath for $10 \mathrm{~min}$ to obtain the maximum leakage of the leaf disks. Electrical conductivity was measured again (L2) after the samples equilibrated at $25^{\circ} \mathrm{C}$, and the electrolyte leakage was estimated as EL\% $=(\mathrm{L} 1 / \mathrm{L} 2) \times 100$.

\subsection{Leaf Adenosine Triphosphate (ATP) Measurements}

Three leaf disks per each subtending to a first position white flower from each plant were excised using a cork borer $(1 \mathrm{~cm}$ in diameter) at the end of the first and seventh night. The leaf disks were placed immediately in tubes containing $5 \mathrm{~mL}$ TRIS solution, and the tubes were put in a boiling water bath for $10 \mathrm{~min}$ for the extraction of ATP. The resulting aliquot was then stored in $1.5 \mathrm{~mL}$ microcentrifuge tubes at $-80^{\circ} \mathrm{C}$. The substrate-enzyme complex of firefly luciferin-luciferase (ATP bioluminescent assay kit, Sigma Chemical Company, St. Louis, MO, USA) that converts the chemical energy associated with ATP into light was used, and the light produced (proportional to the ATP content of the sample) was determined with a 20/20n luminometer (Turner BioSystems Inc., Sunnyvale, CA, USA) and the help of a standard curve. The results were expressed as $\mu \mathrm{g}$ ATP $\mathrm{m}^{-2}$.

\subsection{Glutathione Reductase (GR) Measurements}

Glutathione reductase was extracted and measured from first position white flowers and their subtending leaves at the end of the first and second week after initiation of stress according to the methods described by Loka and Oosterhuis [28]. Excised pistil and leaf tissues were homogenized using a mortar and pestle in an ice-cold extraction solution (10X tissue fresh weight, about $0.1 \mathrm{~g}$ for the pistil, about $0.5 \mathrm{~g}$ for the leaf) comprised of $50 \mathrm{mM}$ PIPES (1,4-piperazinediethanesulfonic acid) buffer ( $\mathrm{pH}$ 6.8), $6 \mathrm{mM}$ cysteine hydrochloride, $10 \mathrm{mM}$ d-isoascorbate, $1 \mathrm{mM}$ ethylenediaminetetraacetic acid, $0.3 \%$ Triton X-100, and 1\% (w/v) soluble polyvinylpyrrolidone (PVP). Solutions were further blended for $1 \mathrm{~min}$ in a tube containing $0.25 \mathrm{~g}$ insoluble PVP and 1 drop of antifoam A emulsion using a homogenizer (Model Polytron; Brinkman Instruments Inc., Palo Alto, CA, USA). Subsequently, 
samples were centrifuged at $12,000 \mathrm{rpm}$ for $20 \mathrm{~min}\left(4^{\circ} \mathrm{C}\right)$, and the supernatants were stored at $-80^{\circ} \mathrm{C}$ for further determination of glutathione reductase content. To each well of a 96-well microtitration plate, a $15.7 \mu \mathrm{L}$ aliquot of enzyme extract from each sample was added to a $300 \mu \mathrm{L}$ reaction solution containing $50 \mathrm{mM}$ Tris- $\mathrm{HCl}$ buffer $(\mathrm{pH}=7.5), 0.15 \mathrm{mM}$ reduced nicotinamide adenine dinucleotide phosphate (NADPH), $0.5 \mathrm{mM}$ oxidized glutathione, and $3 \mathrm{mM} \mathrm{MgCl}_{2}$. Oxidation of NADPH was determined as the decrease in absorbance at $340 \mathrm{~nm}$ during a $1 \mathrm{~min}$ reaction time and was measured using an Ascent Multiscan microplate reader (Molecular Devices Corporation, Sunnyvale, CA, USA), and glutathione reductase activity was expressed as GR units $\mathrm{gr}^{-1} \mathrm{FW}$ (fresh weight).

\subsection{Determination of Soluble Carbohydrates of Cotton Flowers and their Subtending Leaves}

First fruiting position cotton flowers from the 8th and 10th nodes of each plant and their subtending leaves were sampled at the end of the first and second week. Soluble carbohydrate content of the pistils and their subtending leaves was measured according to the method described by Loka and Oosterhuis [28]. The tissues (leaves and excised pistils) were oven dried for 3 days at $50{ }^{\circ} \mathrm{C}$ and then ground with a mortar and pestle. Then $40 \mathrm{mg}$ of the ground tissue were extracted 3 times with $80^{\circ} \mathrm{C}$ aqueous ethanol $(800 \mathrm{~mL}$ ethanol/L), and the samples were centrifuged after each extraction at $5000 \mathrm{rpm}$. Finally the fractions were pooled, and the remaining tissue pellet was kept for extraction and determination of starch. Active charcoal $(30 \mathrm{mg})$ was then added to the pooled fractions in order to remove substances that could interfere with the carbohydrate measurements, and the samples were centrifuged again at $3500 \mathrm{rpm}$ for $15 \mathrm{~min}$ at $4{ }^{\circ} \mathrm{C}$. The supernatant was immediately stored at $-80^{\circ} \mathrm{C}$ for further determination of sucrose, glucose, and fructose with a MultiScan Ascent microplate reader (Thermo Fisher Scientific Inc., Waltham, MA, USA). The glucose (HK) assay kit from Sigma (Sigma Chemical Company, St. Louis, MO, USA) was used. A $20 \mu \mathrm{L}$ aliquot of each extract was pipetted into a well of a microtiter plate, and the plate was incubated at $50{ }^{\circ} \mathrm{C}$ for $40 \mathrm{~min}$ to evaporate ethanol. Ten microliters of water were then added to each well along with $100 \mu \mathrm{L}$ of glucose assay reagent (included in the assay kit), and the plate was incubated again for $15 \mathrm{~min}$ at $30^{\circ} \mathrm{C}$. The absorbance was measured three times at $340 \mathrm{~nm}$ using a microplate reader. Ten microliters of phosphoglucose isomerase $(0.25 \mathrm{EU})$ were added to the extracts in each well of the plate, and the absorbance was again measured at $340 \mathrm{~nm}$. Subsequently, $10 \mu \mathrm{L}$ of invertase (83 EU) was added to the extracts, and the microtiter plate was incubated at $30^{\circ} \mathrm{C}$ for $60 \mathrm{~min}$. The absorbance was measured three times at $340 \mathrm{~nm}$, and the results were expressed in $\mathrm{mg}$ carbohydrate/mg dry weight with the help of a standard curve made of known glucose concentrations $\left(0.4,0.1,0.01,0.001,0.0001 \mathrm{~mL}\right.$ glucose $\left.\mathrm{mL}^{-1}\right)$. The results were expressed as $\mathrm{mg} / \mathrm{mg}$ DW (dry weight). The remaining tissue pellet was used for starch extraction, and $0.5 \mathrm{~mL}$ of $1 \mathrm{M} \mathrm{KOH}$ was added into each sample. The samples were then placed in a boiling water bath for $60 \mathrm{~min}$, and starch was hydrolyzed after additions of $\beta$-amylase and amyloglucosidase according to methods described by Zhao et al. [29]. After centrifugation of the samples at 14,000 rpm for $10 \mathrm{~min}$, the extracts were brought to a final volume of $1.5 \mathrm{~mL}$ with double deionized water. A $20 \mu \mathrm{L}$ aliquot of each extract was pipetted into a well of a microtiter plate, and the glucose concentrations were determined according to the methods used to quantify glucose in the soluble carbohydrate extractions. Glucose content was multiplied by 0.9 to account for water loss after glucose units were connected to form starch [29]. The results were expressed as $\mathrm{mg} \mathrm{mg}^{-1} \mathrm{DW}$ (dry weight).

\subsection{Dry Weight and Number of Reproductive Structures}

The number of reproductive structures per plant, including flower buds, flowers, and young bolls, was recorded at the end of the experiment. Dry weight per reproductive structure and total dry weight of reproductive structures (total reproductive dry weight) were measured and expressed as g.

\subsection{Statistical Analysis}

The experimental design was a two-factor factorial, the two factors being cultivar and temperature, with thirty replications in each temperature treatment and fifteen replications for each cultivar in the 
same temperature treatment. The trends of the two growth chamber studies were similar, and the results were pooled and analyzed using a Student's $t$-test. Means were considered significantly different at $p \leq 0.05$.

\section{Results}

\subsection{Effect of High Night Temperatures on Leaf Gas Exchange}

Net photosynthesis rates of LSWF for ST5288 were significantly lower compared to the control, after one and two weeks, of the treatment imposition (22\% and $25 \%$, respectively). In contrast, net photosynthetic rates of thermotolerant $\mathrm{VH} 260$, were not substantially affected (Figure 1A). Nevertheless, higher than optimum night temperatures, and markedly increased respiration rates of LSWF of both cultivars were obtained. Specifically, respiration rates were almost doubled compared to control for ST5288 at the end of the first week, while an $85 \%$ increase was observed at the end of the second week (Figure 1B). A similar pattern was also observed in LSWF respiration rates of VH260, where an $85 \%$ and $80 \%$ increase were observed at the end of the first and second week, respectively (Figure 1B).
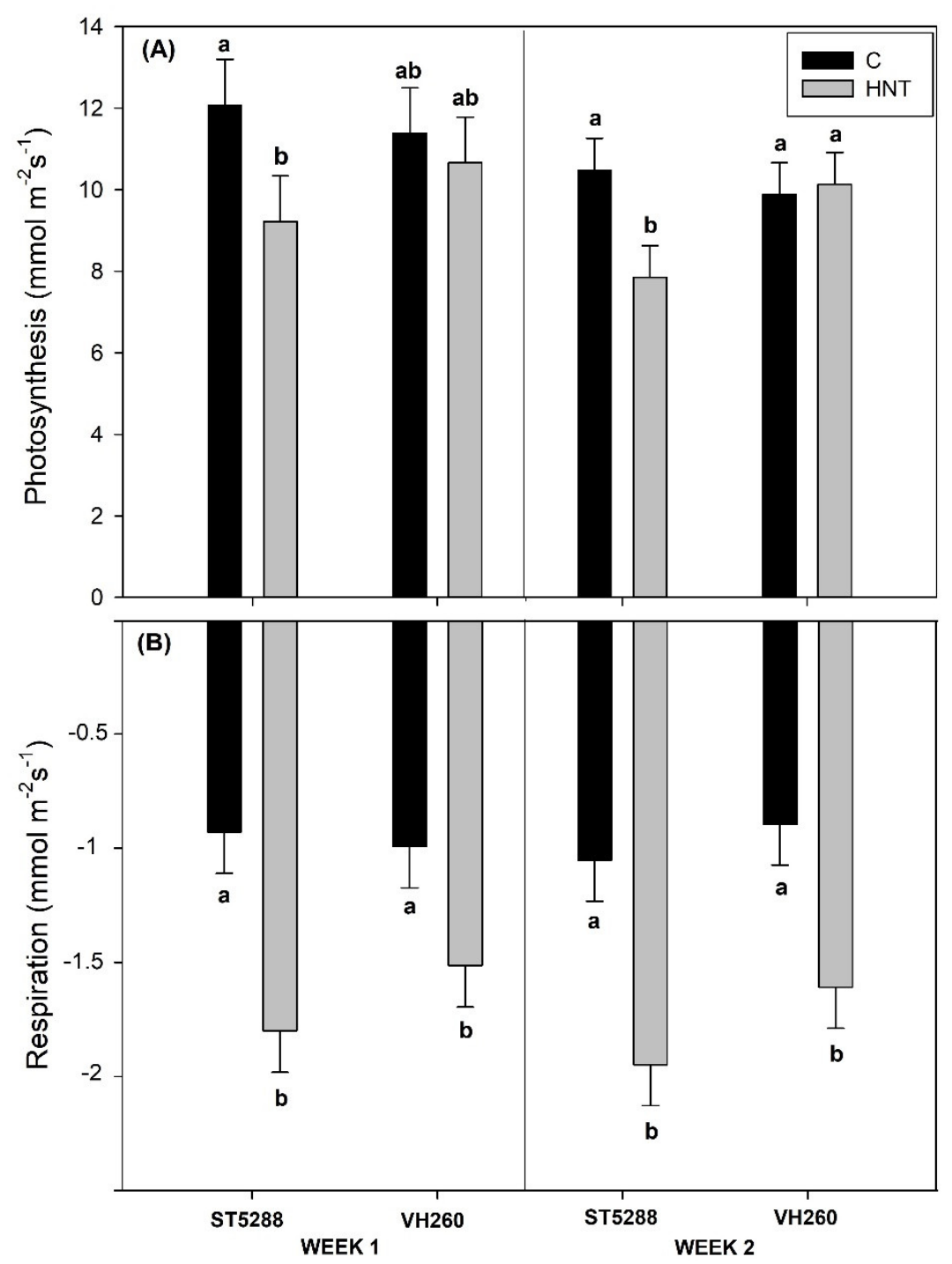

Figure 1. Effect of high night temperatures on subtending leaf net photosynthesis (A) and respiration (B) at the end of the first and second week after initiation of the treatment. Columns connected with different letters are significantly different $(p=0.05)$. Error bars represent \pm 1 standard error. (C: control temperatures $32 / 24{ }^{\circ} \mathrm{C}$, HNT: high night temperatures $32 / 30{ }^{\circ} \mathrm{C}$ ). 


\subsection{Effects of High Night Temperatures on Leaf ATP Content}

High night temperatures substantially decreased LSWF ATP levels of both cultivars. Specifically, after one week of stress, LSWF ATP levels of ST5288 and VH260 decreased by 37 and 27\%, respectively, compared to the control, and similar decreases ( $29 \%$ and $23 \%$ ) were observed at the end of the treatment (Figure 2A).
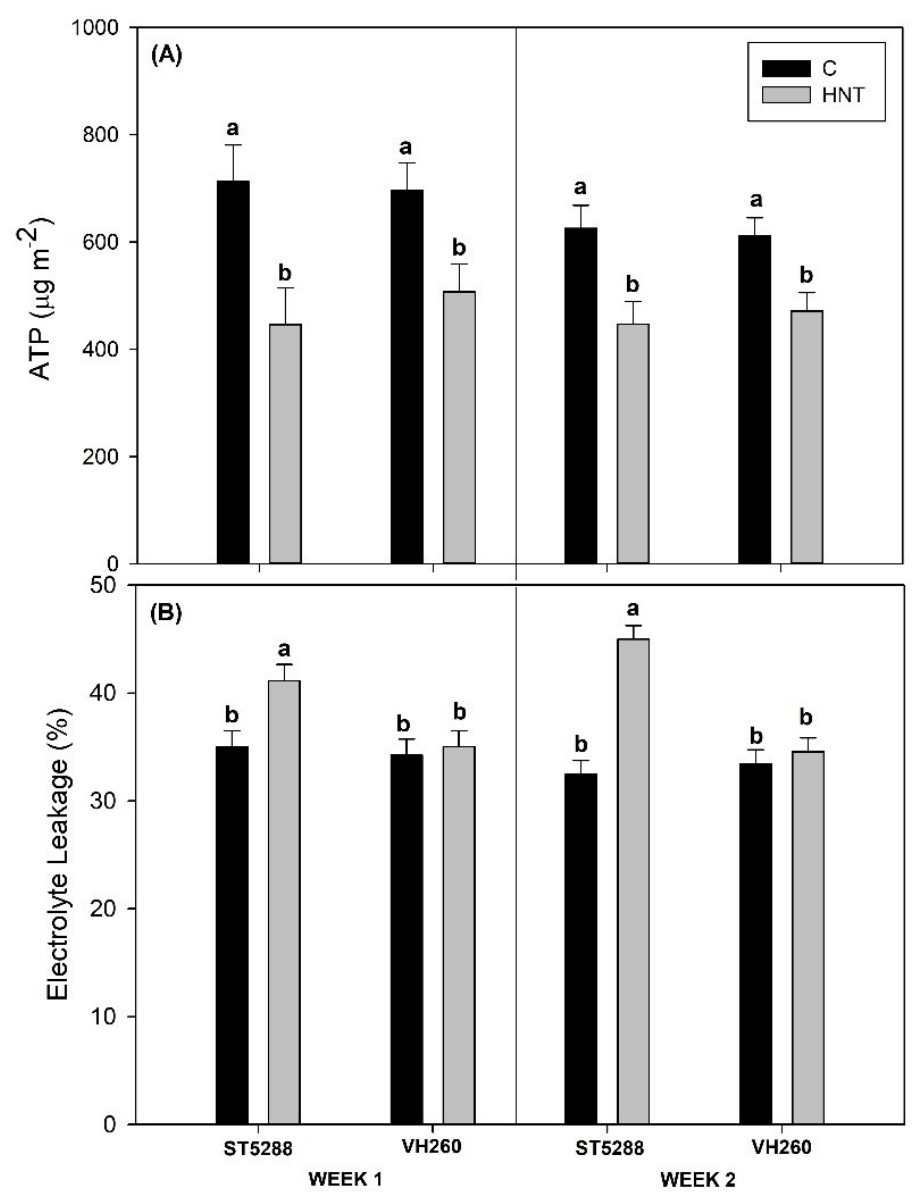

Figure 2. Effect of high night temperatures on subtending leaf ATP levels (A) and electrolyte leakage (B) at the end of the first and second week after initiation of the treatment. Columns connected with different letters are significantly different $(p=0.05)$. Error bars represent \pm 1 standard error. (C: control temperatures $32 / 24{ }^{\circ} \mathrm{C}$, HNT: high night temperatures $32 / 30{ }^{\circ} \mathrm{C}$ ).

\subsection{Effects of High Night Temperatures on Leaf Electrolyte Leakage}

Leaf electrolyte leakage of LSWF of ST5288 were markedly increased by high night temperatures at the end of the first and second week of the treatment (17\% and $38 \%$, respectively). Contrastingly, no significant differences were observed in $\mathrm{VH} 260$, where LSWF membrane leakage rates of heat-stressed plants remained similar to those of the control (Figure 2B).

\subsection{Effects of High Night Temperatures on Leaf and Pistil Glutathione Reductase Contents}

Higher than optimum night temperatures substantially increased LSWF glutathione reductase content of ST5288 by $15 \%$ and $26 \%$ at the end of the first and second week, respectively (Figure 3A). However, that was not observed in VH260 where LSWF glutathione reductase levels of heat-stressed plants remained similar to those of the control (Figure 3A). A differential pattern was observed in the glutathione reductase content of pistils, where no significant difference was detected in ST5288, 
but substantial increases (11\% and 15\%) were noted in VH260 at the end of the first and second week, respectively (Figure 3B).
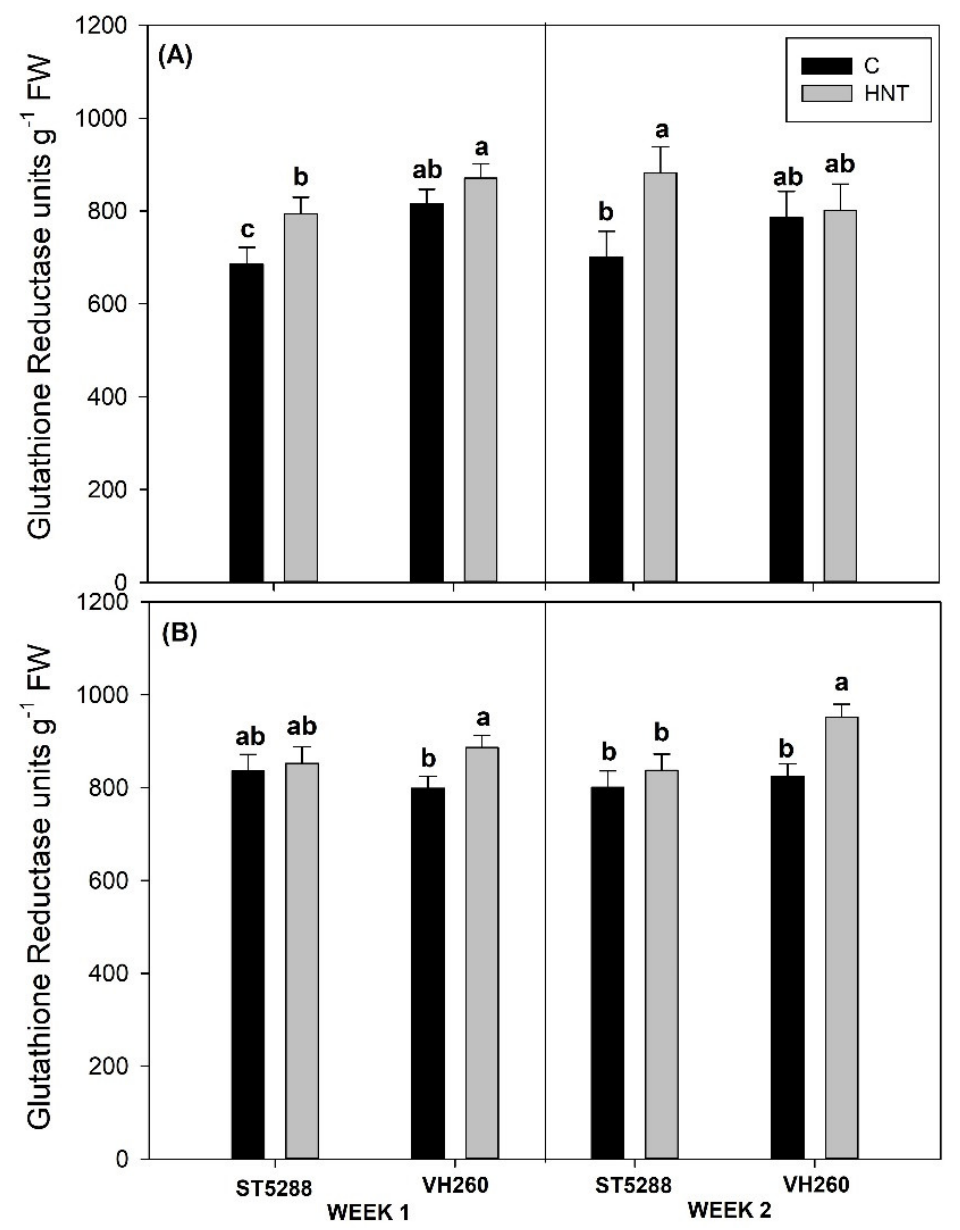

Figure 3. Effect of high night temperatures on subtending leaf glutathione reductase (GR) levels (A) and pistil GR levels (B) at the end of the first and second week after initiation of the treatment. Columns connected with different letters are significantly different $(p=0.05)$. Error bars represent \pm 1 standard error. (C: control temperatures $32 / 24^{\circ} \mathrm{C}$, HNT: high night temperatures $32 / 30^{\circ} \mathrm{C}$ ).

\subsection{Effects of High Night Temperatures on Leaf Carbohydrates Levels}

Higher than optimum night temperatures significantly decreased LSWF hexose content in ST5288 by $15 \%$ and $31 \%$ compared to the control, but had no effect on LSWF hexose content in VH260 (Figure 4A). LSWF sucrose levels of ST5288 were also substantially lower compared to the control after one and two weeks of high night stress imposition ( $24 \%$ and $34 \%$, respectively) (Figure 4B). In contrast, LSWF sucrose levels of VH260 were not affected by the heat stress treatment by the end of the first week, but markedly decreased, by $26 \%$ compared to the control, after two weeks of high night temperatures stress (Figure 4B). In contrast to LSWF hexose and sucrose contents, no response to high night temperatures was observed on LSWF contents of ST5288 and VH260 at the end of the first week. However, LSWF starch contents of ST5288 and VH260 were lower by 7\% and 9\%, respectively, compared to the control by the end of the treatment (Figure 4C). 

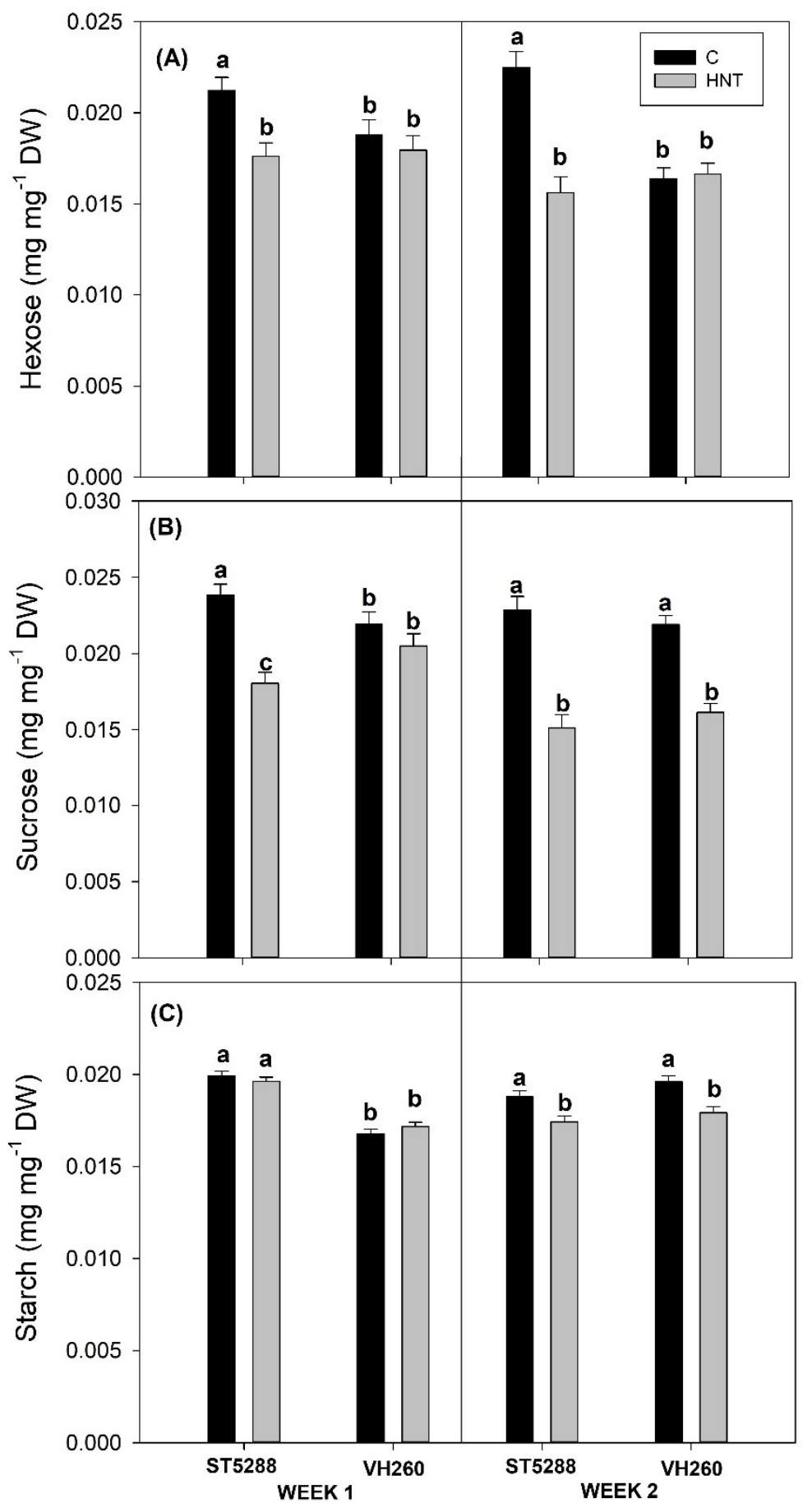

Figure 4. Effect of high night temperatures on subtending leaf hexose (A), sucrose (B), and starch (C) concentrations at the end of the first and second week after initiation of the treatment. Columns connected with different letters are significantly different $(p=0.05)$. Error bars represent \pm 1 standard error. (C: control temperatures $32 / 24^{\circ} \mathrm{C}$, HNT: high night temperatures $32 / 30{ }^{\circ} \mathrm{C}$ ).

\subsection{Effects of High Night Temperatures on Pistil Carbohydrates Contents}

High night temperatures did not prompt a response to pistil hexose levels of ST5288 in contrast to those of VH260 that were markedly increased by $31 \%$ compared to the control. A differential response was observed by the end of the treatment, with pistil hexose content of ST5288 being substantially lower (20\%) compared to the control, while VH260 pistil hexose content remaining markedly higher (39\%) compared to the control (Figure 5A). Pistil sucrose content was substantially increased at both sampling 
times by $43 \%$ and $55 \%$, respectively, in ST5288 under high night temperature conditions compared to the control, but no significant differences were observed in VH260 (Figure 5B). Furthermore, higher than optimum night temperatures had no effect on pistil starch content on either cultivar by the end of the first week, but a marked decrease was observed in pistil starch content of ST5288 at the end of the treatment (Figure 5C).
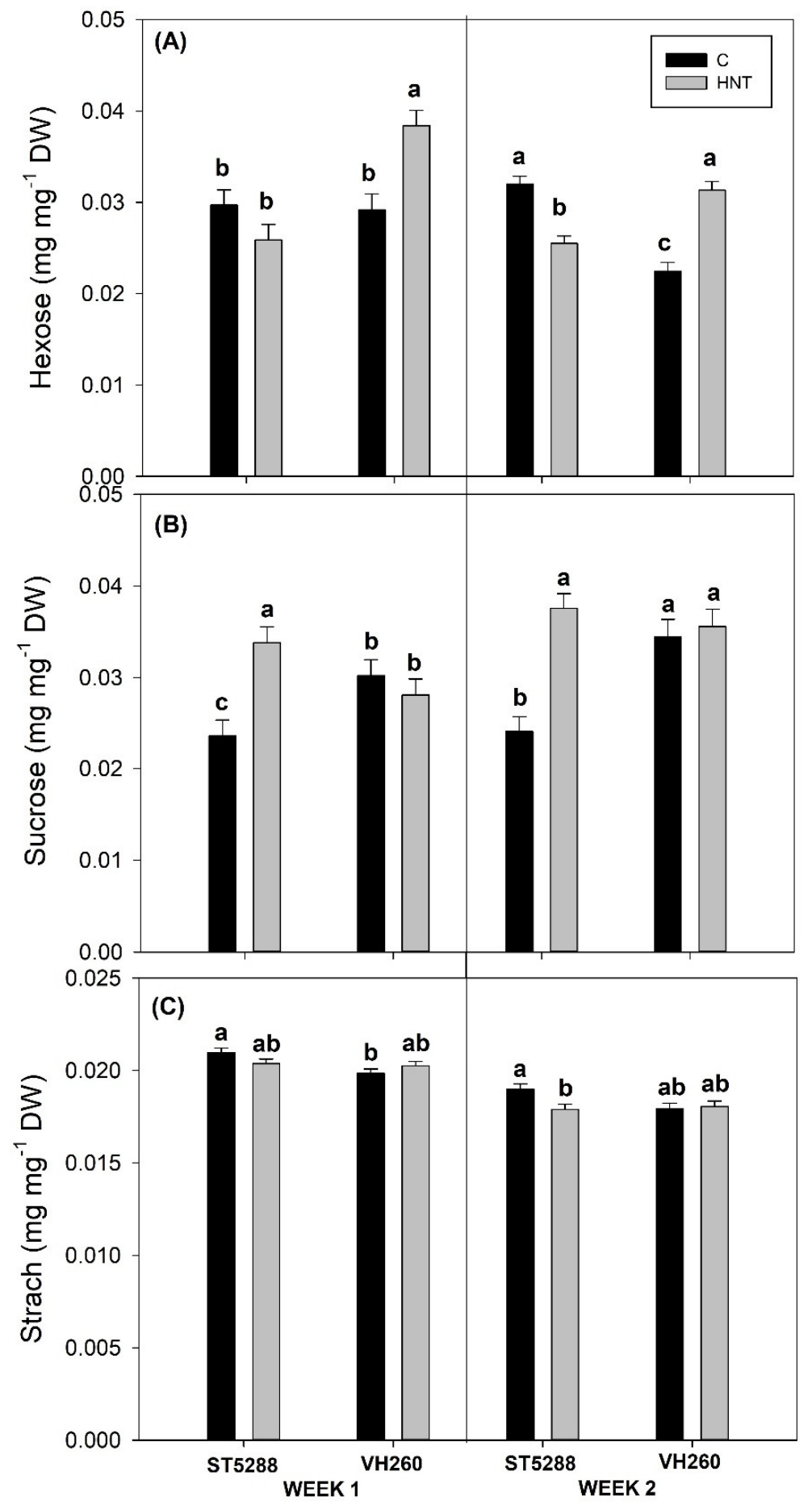

Figure 5. Effect of high night temperatures on pistil hexose (A), sucrose (B), and starch (C) content at the end of the first and second week after initiation of the treatment. Columns connected with different letters are significantly different $(p=0.05)$. Error bars represent \pm 1 standard error. (C: control temperatures $32 / 24{ }^{\circ} \mathrm{C}$, HNT: high night temperatures $32 / 30^{\circ} \mathrm{C}$ ). 


\subsection{Effect of High Night Temperatures on Dry Weight and Number of Reproductive Structures}

VH260 had a higher total reproductive weight under high night temperatures conditions compared to ST5288, but high night temperatures resulted in significant yet similar $(20 \%)$ decreases in total reproductive dry weight of both cultivars compared to their respective controls. The reductions in ST5288 were attributed to the decreased number of reproductive structures per plant (18\%). In contrast, VH260 was able to increase its number of reproductive structures per plant by $13 \%$. On the other hand, the decreases in total reproductive dry weight observed in VHS260 were attributed mainly to reductions in the dry weight per reproductive structure (31\%), whereas no effect of high night temperatures stress was observed on the dry weight per reproductive structure of ST5288 (Table 1).

Table 1. Effect of high night temperatures on total reproductive dry weight, number of reproductive structures/plant, and individual reproductive unit dry weight at the end of the second week after treatment initiation. Columns connected with different letters are significantly different $(p=0.05)$. (C: control temperatures $32 / 24{ }^{\circ} \mathrm{C}$, HNT: high night temperatures $32 / 30{ }^{\circ} \mathrm{C}$ ).

\begin{tabular}{ccccc}
\hline Cultivar & \multicolumn{2}{c}{ ST5288 } & \multicolumn{2}{c}{ VH260 } \\
\hline Treatment & C & HNT & C & HNT \\
Total reproductive DW $(\mathrm{g})^{1}$ & $14.71 \mathrm{~b}$ & $11.75 \mathrm{~d}$ & $16.3 \mathrm{a}$ & $13.05 \mathrm{c}$ \\
Reproductive structures & $13.2 \mathrm{a}$ & $10.48 \mathrm{~b}$ & $10.4 \mathrm{~b}$ & $11.78 \mathrm{ab}$ \\
number/plant & $1.17 \mathrm{~b}$ & $1.18 \mathrm{~b}$ & $1.69 \mathrm{a}$ & $1.16 \mathrm{~b}$ \\
\hline Reproductive DW/structure $(\mathrm{g})$ &
\end{tabular}

${ }^{1}$ Includes flower buds, flowers, and young bolls.

\section{Discussion}

Higher than optimum temperatures have long been known to adversely affect several physiological and metabolic processes with detrimental effects on plant growth and yield. To that end, extensive efforts have been undertaken and heat-tolerant cultivars have been introduced [21-24]; however, their efficiency against high night temperatures has not been studied. Respiration, a key metabolic process closely related to crop growth, has long been known for its sensitivity to heat stress [30] and increased respiration rates under higher than optimum temperatures have been reported in a variety of crops, including cotton [8-10,13]. Studies, however, have suggested that cultivars that can maintain low respiration rates under conditions of heat stress, either through more efficient energy use or reduced maintenance respiration, are more heat tolerant [31,32]. In contrast to those studies, high night temperatures in our experiments increased respiration rates of both cultivars, indicating that $\mathrm{VH} 260$ was unable to prevent increases in its respiration rates. In contrast, VH260 was able to maintain its net photosynthetic rates, while high night temperatures markedly decreased net photosynthetic rates of ST5288. Photosynthesis is one of the most heat-labile processes in plants due to the sensitivity of PS II, and several researchers have reported the adverse effect higher than optimum day temperatures has on photosynthesis [1,22]. In cotton, however, Schrader et al. [33] observed that heating dark-adapted leaves resulted in decreased photosynthetic efficiency due to an increase in thylakoid permeability. In support of that observation, Prasad et al. [8,10], in experiments with wheat and sorghum, reported that high night temperatures decreased photosynthesis and that was attributed to compromises of cell membrane integrity due to over-production of reactive oxygen species (ROS) from increased respiration rates. Decreases in cell membrane integrity appear to be the reason for the decreased net photosynthetic rates of ST5288 observed in our study, since electrolyte leakage, a measure of cell membrane integrity, was substantially increased under high night temperatures stress, indicating significant cell membrane damage [26,27]. Contrastingly, electrolyte leakage of VH260 remained unaffected, suggesting that $\mathrm{VH} 260$ was able to maintain its cell membrane integrity and as a result managed to prevent decreases in its net photosynthetic rates. Similar to our results, Snider et al. [22] observed that high day temperatures had no significant effect on net photosynthetic rates of VH260, 
while significant decreases were observed in their thermosensitive cultivar. According to the authors, that was attributed to the maintenance of high GR levels in VH260 under heat stress conditions that were able to protect the photosynthetic system from damage by reactive oxidative species (ROS). In accordance with their results, GR levels of VH260 in our study remained unaffected for the duration of heat stress. However, even though high night temperatures increased GR levels of ST5288 to similar to VH260 GR levels, they were unable to prevent reductions in cell membrane integrity and net photosynthesis, leading us to speculate that GR had a rather minimal antioxidative capacity under high night temperatures stress, and the increased cell membrane integrity of VH260 was the main reason for the maintenance of photosynthetic rates. Since membrane integrity and thermostability is largely determined by the membrane's degree of saturation, and GR is not the only antioxidant controlling ROS accumulation. Further research into the cell membrane composition and antioxidant capacity of VH260 could provide a better insight into its increased cell membrane stability.

In addition to the formation of ROS and cell membrane damage, disruptions in photosynthesis and respiration, due to higher than optimum temperatures, have a significant effect on the plant's energy balance, since both of them are involved in ATP synthesis [32]. Increases in respiration, which is the main provider of ATP in plants, is a common response to heat stress, since energy costs of repair mechanisms for maintenance of cellular homeostasis are increased [34,35]. In our study, higher than optimum temperatures resulted in substantial decreases in LSWF ATP content in both cultivars, despite the significant increases in respiration rates. While the lower LSWF ATP content in ST5288 could be partially attributed to its decreased photosynthetic rates, the similar reductions in LSWF ATP content of VH260 lead us to speculate that the increased energy demands for synthesis of protective compounds [36,37], and maintenance of ATP-demanding processes, such as phloem loading [32], were the main reason for the substantially reduced LSWF ATP levels of both cultivars.

Apart from energy supply, disruptions in photosynthesis and respiration can have a significant effect on leaf carbohydrate content, since they respectively control carbon fixation and utilization [38,39]. In our study, LSWF starch and sucrose levels of both cultivars were decreased under conditions of high night temperatures. Comparable decreases were also observed in soybean and were attributed to decreases in leaf net photosynthetic rates [9], which is in accordance with our findings in ST5288 but not in VH260, whose net photosynthetic rates remained unaltered. Starch, as the main storage form of carbohydrates, is accumulated during the day in order to sustain carbohydrate demand during the night. However, its degradation during the day indicated that photosynthetic rates of VH260 were apparently insufficient to maintain growth under heat stress conditions [40]. A similar explanation could also be provided for the decreases in LSWF sucrose content of VH260, but taking in consideration the high sensitivity of sucrose metabolizing enzymes to temperature changes [41] we speculate that the observed reductions could also be due to decreased activities of sucrose synthesizing enzyme sucrose phosphate synthase (SPS) or increased activities of sucrose cleaving enzymes sucrose synthase (SS) and invertase (INV). In support of our speculation, Kaushal et al. [42] reported that heat-stressed chickpea leaves had lower SPS activity compared to control, while increased INV activities were observed under conditions of heat stress [43]. In contrast to LSWF sucrose content, decreases in LSWF hexose content were observed only in ST528 but not in VH260. Kaushal et al. [42] reported similar decreases in hexose content of heat-sensitive chickpea genotypes, and they were attributed to lower photosynthetic rates as well as decreased INV activity, leading us to assume that VH260 was able to maintain its hexose content possibly due to its increased INV activity. However, since activities of sucrose metabolizing enzymes were not quantified in this study, further research is required in order to confirm these assumptions.

Reproductive success is greatly dependent on leaf carbohydrate supply [10,44], as well as on photoassimilate translocation to reproductive structures [45] and redox homeostasis of them [44-46]. According to our results, a marked increase was observed in the sucrose content of ST5288 reproductive structures, whereas hexose and starch contents were significantly decreased. Heat stress has been reported to inhibit assimilate translocation and result in substantial reductions in the carbohydrate content of reproductive structures [47]. However, this over-accumulation of sucrose, despite the 
substantial decreases in its LSWF carbohydrate content, suggests that high night temperatures did not have an effect on sucrose translocation. Since assimilate translocation is determined by both sink strength and competition between sinks for assimilates [48], the lower number of retained reproductive structures in ST5288 would have effectively reduced competition for substrates and hence allow the maintenance of sucrose translocation. Additionally, a decrease in sink strength, indicated by reduced activities of sucrose cleaving enzymes, should also be considered, especially since hexose contents of ST5288 reproductive structures were substantially reduced. Nevertheless, increases in sucrose content have also been associated with the antioxidant role that sucrose assumes under conditions of abiotic stress [49]. Pistil GR levels of ST5288, in our study, remained unaffected under conditions of high night temperatures, suggesting that the antioxidant mechanism of pistils was rather unresponsive to stress, inducing as a result further starch degradation and over-accumulation of sucrose in the heat-stressed pistils of ST5288. In support of our suggestion, Snider et al. [44] reported marked increases in GR of heat stressed pistils accompanied by concomitant decreases in pistil sucrose content, which according to the authors indicated a possible connection between those two responses. In contrast to ST5288, pistil sucrose and starch contents of VH260 remained unaffected by the high night temperature regime, whereas pistil hexose content was markedly increased. The lack of an effect of the decreased LSWF sucrose content on pistil sucrose content of VH260, despite the maintenance of the number of reproductive structures, leads us to suggest that VH260 managed to allocate its photoassimilates in a more efficient way compared to ST5288. Furthermore, the increases in pistil hexose content indicated that activities of sucrose-cleaving enzymes, and hence sink strength, was not inhibited under conditions of high night temperatures. Comparable to our results, Kaushal et al. [42] reported increased hexose content in the heat-stress anthers of heat-tolerant chickpea cultivars, which were attributed to increased INV activities. In contrast to ST5288, pistil GR content of VH260 was markedly increased under conditions of high night temperatures This could be attributed to higher pistil GR observed in VH260; however, further research needs to be dedicated in the responses of antioxidant and carbohydrate metabolism of cotton under conditions of high night temperature stress in order to confirm those assumptions.

Despite the different physiological and biochemical responses observed between the two cultivars in our study, high night temperatures resulted in significant, yet similar, decreases compared to control on total reproductive dry weight of both cultivars. Further analysis, however, revealed that the reductions in total reproductive dry weight of ST5288 were associated with decreases in number of reproductive structures per plant, while in VH260, they were due to decreases in the dry weight per reproductive structure. Abscission of reproductive structures, with the exception of white flowers, in cotton, is a naturally occurring procedure, as the plant tries to balance the sink's (reproductive structures) demand for photoassimilates with the source (leaf) availability of photoassimilates [50]. However, abiotic stresses have been shown to exacerbate shedding of reproductive structures, mainly due to reductions in leaf photosynthetic rates that result in perturbations of carbohydrate metabolism and availability of leaves and reproductive structures [51]. This appears to be the case in our study, where the reductions in LSWF photosynthetic rates of ST5288 were accompanied by decreases in LSWF carbohydrate contents, which led the plants to promptly decrease their number of reproductive structures. A different pattern was observed in VH260, where the maintenance of net photosynthetic rates allowed the plants to retain its LSWF carbohydrate content for longer and prevent abscission of reproductive structures. However, despite the increase in pistil GR levels and maintenance of pistil carbohydrate content, significant decreases were observed in the dry weight per reproductive structure in $\mathrm{VH} 260$, confirming the fact that plants that maintain a heavy load of reproductive structures often fail to achieve optimum reproductive structure weight, due to the increased competition between sinks for photoassimilates [52]. In spite of the similar decreases compared to control on total reproductive dry weight of both cultivars, total reproductive dry weight of VH260 under conditions of high temperatures was significantly higher compared to that of ST5288, indicating that VH260 was more heat tolerant compared to ST5288. Comparable to our results, Xu et al. [24], in their study with two cotton cultivars 
differing in thermotolerance and subjected to a short-term ( 5 days) heat stress during the day, reported that the heat tolerant cultivar had a higher yield compared to the sensitive cultivar. In contrast to our results, that was attributed to the increased boll weight of the heat tolerant cultivar despite the similar abscission rates of both cultivars. We speculate that the differences in stress imposition both in terms of duration and time (day vs. night), as well as the use of different cultivars, are the reasons for the differential responses observed between their study and ours.

In conclusion, high night temperatures resulted in significant decreases in total reproductive weight in the standard cultivar ST5288 but not in the heat-tolerant VH260, indicating that heat tolerant cultivars selected under high day temperatures are also efficient under increased night temperatures. However, taking into consideration the large variability that exists in terms of heat tolerance in cotton, further studies that include more genotypes are required in order to ascertain cotton's heat tolerance under both high day and night temperature conditions. The results also indicated that net photosynthetic rates and cell membrane integrity could be useful indicators for heat tolerance evaluation under high night temperature stress; however, further research into carbohydrate and antioxidant metabolism of cotton's reproductive structures would provide useful information into the mechanisms of heat tolerance in cotton.

Author Contributions: Conceptualization: D.A.L. and D.M.O.; Methodology, Investigation, Data analysis: D.A.L.; Writing-Original Draft Preparation: D.A.L.; Writing-Review and Editing: D.A.L. and D.M.O. All authors have read and agreed to the published version of the manuscript.

Funding: This research received no external funding.

Conflicts of Interest: The authors declare no conflict of interest.

\section{References}

1. Wahid, A.; Gelani, S.; Ashraf, M.; Foolad, M.R. Heat tolerance in plants: An overview. Environ. Exp. Bot. 2007, 61, 199-223.

2. Giorno, F.; Wolters-Arts, M.; Mariani, C.; Rieu, I. Ensuring reproduction at high temperatures: The heat stress response during anther and pollen development. Plants 2013, 2, 489-506. [CrossRef]

3. Parry, M.L.; Canziani, O.F.; Palutikof, J.P.; van der Linden, P.J.; Hanson, C.E. (Eds.) IPCC (Intergovermental Panel on Climate Change) Climate change 2007: Impacts, adaptation and vulnerability. In Contribution of Working Group II to Fourth Assessment Report of the Intergovernmental Panel on Climate Change; Cambridge University Press: Cambridge, UK, 2007.

4. Alward, R.D.; Detling, J.K.; Milchunas, D.G. Grassland vegetation changes and nocturnal globe warming. Science 1999, 283, 229-231.

5. Bita, C.; Gerats, T. Plant tolerance to high temperature in a changing environment: Scientific fundamentals and production of heat stress-tolerant crops. Front. Plant Sci. 2013, 4, 273.

6. Fahad, S.; Bajwa, A.A.; Nazir, U.; Anjum, S.A.; Farooq, A.; Zohaib, A.; Sadia, A.; Wu, C.; Wang, D.; Huang, J. Crop production under drought and heat stress: Plant responses and management options. Front. Plant Sci. 2017, 8, 1147.

7. Barnabas, B.; Jager, K.; Feher, A. The effect of drought and heat stress on reproductive processes in cereals. Plant Cell Environ. 2008, 31, 11-38.

8. Prasad, P.V.V.; Pisipati, S.R.; Ristic, Z.; Bukovnik, U.; Fritz, A.K. Impact of nighttime temperature on physiology and growth of spring wheat. Crop Sci. 2008, 48, 2372-2380.

9. Djanaguiraman, M.; Prasad, P.V.V.; Schapaugh, W.T. High day- or nighttime temperature alters leaf assimilation, reproductive success, and phosphatidic acid of pollen grain in soybean [Glycine max (L.) Merr.]. Crop Sci. 2013, 53, 1594-1604.

10. Prasad, P.V.V.; Djanaguiraman, M. High night temperature decreases leaf photosynthesis and pollen function in grain sorghum. Funct. Plant Biol. 2011, 38, 993-1003.

11. Ahmed, F.E.; Hall, A.E. Heat injury during early floral bud development in cowpea. Crop Sci. 1993, 33, 764-767.

12. Mohammed, A.R.; Tarpley, L. Effects of high night temperature and spikelet position on yield-related parameters of rice (Oryza sativa L.) plants. Eur. J. Agron. 2010, 33, 117-123. [CrossRef] 
13. Mohammed, A.R.; Tarpley, L. Impact of high nighttime temperature on respiration, membrane stability, antioxidant capacity, and yield of rice plants. Crop Sci. 2009, 49, 313-322. [CrossRef]

14. Singh, R.R.; Prasad, P.V.V.; Sunita, K.; Giri, S.N.; Reddy, K.R. Influence of high temperature and breeding for heat tolerance in cotton: A review. Adv. Agr. 2007, 93, 313-385.

15. Cottee, N.S.; Tan, D.K.Y.; Bange, M.P.; Cothren, J.T.; Campbell, L.C. Multi-level determination of heat tolerance in cotton (Gossypium hirsutum L.) under field conditions. Crop Sci. 2010, 50, 2553-2564.

16. Oosterhuis, D.M.; Snider, J.L. High temperature stress on floral development and yield of cotton. In Stress Physiology in Cotton; Oosterhuis, D.M., Ed.; The Cotton Foundation: Cordova, TN, USA, 2011; pp. 1-24.

17. Yoon, S.T.; Hoogenboom, G.; Flitcroft, I.; Bannayan, M. Growth and development of cotton (Gossypium hirsutum L.) in response to $\mathrm{CO}_{2}$ enrichment under two different temperature regimes. Environ. Exp. Bot. 2009, 67, 178-187. [CrossRef]

18. Arevalo, L.M.; Oosterhuis, D.M.; Coker, D.L.; Brown, S.R. Physiological response of cotton to high night temperatures. Am. J. Plant Sci. Biotech. 2008, 2, 63-68.

19. Echer, F.R.; Oosterhuis, D.M.; Loka, D.A.; Rosolem, C.A. High night temperatures during the floral bud stage increase the abscission of reproductive structures in cotton. J. Agron. Crop Sci. 2014, 200, 191-198. [CrossRef]

20. Loka, D.A.; Oosterhuis, D.M. Increased night temperatures during cotton's early reproductive stage affect leaf physiology and flower bud carbohydrate content decreasing flower bud retention. J. Agron. Crop Sci. 2016, 202, 518-529.

21. Singh, K.; Wijewardana, C.; Gajanayake, B.; Lokhande, S.; Wallace, T.; Jones, D.; Reddy, K.R. Genotypic variability among cotton cultivars for heat and drought tolerance using reproductive and physiological traits. Euphytica 2018, 214, 57.

22. Snider, J.L.; Oosterhuis, D.M.; Kawakami, E.M. Genotypic differences in thermotolerance are dependent upon prestress capacity for antioxidant protection on the photosynthetic apparatus in Gossypium hirsutum. Physiol. Plant. 2010, 138, 268-277. [CrossRef]

23. Snider, J.L.; Oosterhuis, D.M.; Kawakami, E.M. Mechanisms of reproductive thermotolerance in Gosyypium hirsutum: The effect of genotype and exogenous calcium application. J. Agron. Crop Sci. 2011, 197, 228-236. [CrossRef]

24. Xu, W.; Zhou, Z.; Zhan, D.; Zhao, W.; Meng, Y.; Chen, B.; Liu, W.; Wang, Y. The difference in the formation of thermotolerance of two cotton cultivars with different heat tolerance. Arch. Agron. Soil Sci. 2019, 66, 58-69. [CrossRef]

25. Ashley, D.A. ${ }^{14}$ C-labelled photosynthate translocation and utilization in cotton plants. Crop Sci. 1972, 12, 60. [CrossRef]

26. Rahman, H.; Malik, S.; Saleem, M. Heat tolerance of upland cotton during the fruiting stage evaluated using cellular membrane thermostability. Field Crops Res. 2004, 85, 149-158. [CrossRef]

27. Martineau, J.R.; Specht, J.E.; Williams, J.H.; Sullivan, C.Y. Temperature tolerance in soybeans. I. Evaluation of a technique for assessing cellular membrane thermostability. Crop Sci. 1979, 19, 75-78. [CrossRef]

28. Loka, D.A.; Oosterhuis, D.M. Water-deficit stress on pistil biochemistry and leaf physiology in cotton (Gossypium hirsutum L.). S. Afr. J. Bot. 2014, 93, 131-136. [CrossRef]

29. Zhao, D.; MacKown, C.T.; Starks, P.J.; Kindiger, B.K. Interspecies variation of forage nutritive value and nonstructural carbohydrates in perennial cool-season grasses. Agron. J. 2008, 100, 837-844. [CrossRef]

30. Bednarz, C.W.; van Iersel, M.W. Temperature response of whole plant $\mathrm{CO}_{2}$ exchange rates of four upland cotton cultivars differing in leaf shape and pubescence. Commun. Soil Sci. Plant Anal. 2001, 32, 2485-2501. [CrossRef]

31. Almeselmani, M.; Deshmukh, P.S.; Chinnusamy, V. Effects of prolonged high temperature stress on respiration, photosynthesis and gene expression in wheat (Triticum aestivum L.) varieties differing in their thermotoleranrce. Plant Stress 2012, 6, 25-32.

32. Posch, B.C.; Kariyasawam, B.D.; Bramley, H.; Coast, O.; Richards, R.A.; Reynolds, M.P.; Trethowan, R.; Atkin, O.K. Exploring high temperature responses of photosynthesis and respiration to improve heat tolerance in wheat. J. Exp. Bot. 2019, 70, 5051-5069.

33. Schrader, S.M.; Wise, R.R.; Wacholtz, W.F.; Ort, D.R.; Sharkey, T.D. Thylakoid membrane responses to moderately high leaf temperature in Pima cotton. Plant Cell Environ. 2004, 27, 725-735. [CrossRef]

34. Hong, S.W.; Vierling, E. HSP 101 is necessary for heat tolerance but dispensable for development and germination in the absence of stress. Plant J. 2001, 27, 25-35. [CrossRef] [PubMed] 
35. McCree, K.J. Equations for the dark respiration of white clover and grain sorghum, as functions of dry weight, photosynthetic rate and temperature. Crop Sci. 1974, 14, 509-514. [CrossRef]

36. Burke, J.J.; Hatfield, J.L.; Klein, R.D.; Mullet, J.E. Accumulation of heat shock proteins in field-grown cotton. Plant Physiol. 1985, 78, 394-398. [CrossRef]

37. Macario, A.J.; Conway de Macario, E. Molecular chaperones: Multiple functions, pathologies and potential applications. Front Biosci. 2007, 12, 2588-2600. [CrossRef]

38. Paulsen, G.M. High temperature responses of crop plants. In Physiology and Determination of Crop Yield; Boote, K.J., Jackie, M.B., Thomas, R.S., Gary, M.P., Eds.; American Society of Agronomy: Madison, WN, USA, 1994; pp. 365-389.

39. Huang, B.; Liu, X.; Fry, J.D. Shoot physiological responses of two bentgrass cultivars to high temperature and poor soil aeration. Crop Sci. 1998, 38, 1219-1244. [CrossRef]

40. Thalmann, M.; Santelia, D. Starch as determinant of plant fitness under abiotic stress. New Phytol. 2017, 214, 943-951. [CrossRef] [PubMed]

41. Ruan, Y.L.; Jin, Y.; Yang, Y.J.; Guo, J.; Boyer, J.S. Sugar input, metabolism and signaling mediated by invertase: Roles in development, yield potential, and response to drought and heat. Mol. Plant 2010, 3, 942-955. [CrossRef]

42. Kaushal, N.; Awasthi, R.; Gupta, K.; Gaur, P.; Siddique, K.H.M.; Nayyar, H. Heat-stressed-induced reproductive failures in chickpea (Cicer arietinum L.) are associated with impaired sucrose metabolism in leaves and anthers. Funct. Plant Biol. 2013, 40, 1334-1349. [CrossRef] [PubMed]

43. Awasthi, R.; Kaushal, N.; Vadez, V.; Turner, N.C.; Nayyar, H. Individual and combined effects of transient drought and heat stress on carbon assimilation and seed filling in chickpea. Funct. Plant Biol. 2014, 41, 1148-1167. [CrossRef]

44. Snider, J.L.; Oosterhuis, D.M.; Skulman, B.W.; Kawakami, E.M. Heat stress-induced limitations to reproductive success in Gossypium hirsutum L. Physiol. Plant. 2009, 137, 125-138. [CrossRef]

45. McNairn, R.B. Phloem translocation and heat-induced callose formation in field-grown Gossypium hirsutum L. Plant Physiol. 1972, 50, 366-370. [CrossRef]

46. Zinta, G.; Khan, A.; Abdelgawad, H.; Verma, V.; Shrivastava, A.K. Unveiling the redox control of plant reproductive development during abiotic stress. Front. Plant Sci. 2016, 7, 700. [CrossRef]

47. Plaut, Z.; Butow, B.J.; Blumenthal, C.S.; Wrigley, C.W. Transport of dry matter into developing wheat kernels and its contribution to grain yield under post-anthesis water deficit and elevated temperature. Field Crops Res. 2004, 86, 185-198. [CrossRef]

48. Ruan, Y.L. Sucrose metabolism: Gateway to diverse carbon use and sugar signaling. Annu. Rev. Plant Biol. 2014, 65, 33-67. [CrossRef]

49. Couee, I.; Sulmon, C.; Gouesbet, G.; El Amrani, A. Involvement of soluble sugars in reactive oxygen species balance and response to oxidative stress in plants. J. Exp. Bot. 2006, 57, 449-459. [CrossRef]

50. Constable, G.A.; Oosterhuis, D.M. Physiology of Cotton; Stewart, J.M., Oosterhuis, D.M., Heitholt, J.J., Mauney, J.R., Eds.; Springer: Dordrecht, Germany, 2010.

51. Zhao, D.; Reddy, K.R.; Kakani, V.G.; Koti, S.; Gao, W. Physiological causes of cotton fruit abscission under conditions of high temperature and enhanced ultraviolet-B radiation. Physiol. Plant. 2005, 124, 189-199. [CrossRef]

52. Patterson, L.L.; Buxton, D.R.; Briggs, R.E. Fruiting in cotton as affected by controlled boll set. Agron. J. 1978, 70, 118-122. [CrossRef]

(C) 2020 by the authors. Licensee MDPI, Basel, Switzerland. This article is an open access article distributed under the terms and conditions of the Creative Commons Attribution (CC BY) license (http://creativecommons.org/licenses/by/4.0/). 